\title{
Herpes Simplex Virus Infection in Pregnancy
}

\author{
Gianluca Straface, ${ }^{1}$ Alessia Selmin, ${ }^{1}$ Vincenzo Zanardo, ${ }^{1}$ Marco De Santis, ${ }^{2}$ \\ Alfredo Ercoli, ${ }^{1}$ and Giovanni Scambia ${ }^{2}$
}

${ }^{1}$ Department of Obstetrics and Gynaecology Policlinico Abano Terme, 35031 Abano Terme (PD), Italy

${ }^{2}$ Department of Obstetrics and Gynaecology, Catholic University of Sacred Heart, 00100 Roma, Italy

Correspondence should be addressed to Gianluca Straface, gianluca.straface@casacura.it

Received 11 January 2012; Accepted 12 February 2012

Academic Editor: Francesco De Seta

Copyright (C) 2012 Gianluca Straface et al. This is an open access article distributed under the Creative Commons Attribution License, which permits unrestricted use, distribution, and reproduction in any medium, provided the original work is properly cited.

\begin{abstract}
Infection with herpes simplex is one of the most common sexually transmitted infections. Because the infection is common in women of reproductive age it can be contracted and transmitted to the fetus during pregnancy and the newborn. Herpes simplex virus is an important cause of neonatal infection, which can lead to death or long-term disabilities. Rarely in the uterus, it occurs frequently during the transmission delivery. The greatest risk of transmission to the fetus and the newborn occurs in case of an initial maternal infection contracted in the second half of pregnancy. The risk of transmission of maternal-fetal-neonatal herpes simplex can be decreased by performing a treatment with antiviral drugs or resorting to a caesarean section in some specific cases. The purpose of this paper is to provide recommendations on management of herpes simplex infections in pregnancy and strategies to prevent transmission from mother to fetus.
\end{abstract}

\section{Introduction}

Herpes simplex virus (HSV) is an ubiquitous, enveloped, and doublestranded DNA virus, belonging to the family of Herpesviridae transmitted across mucosal membranes and nonintact skin, that migrate to nerve tissues, where they persist in a latent state. HSV-1 predominates in orofacial lesions, and it is typically found in the trigeminal ganglia, whereas HSV-2 is most commonly found in the lumbosacral ganglia [1]. Nevertheless these viruses can infect both orofacial areas and the genital tract. In some developed countries type 1 has recently emerged as the prominent causative agent in genital lesions. Changes in sexual behaviours of young adults may partly explain its higher incidence $[2,3]$.

A first primary infection develops when a susceptible person (lacking of preexisting HSV-1 and HSV-2 antibodies) is exposed to HSV.

Indeed, a first nonprimary episode occurs when a person with preexisting HSV antibodies (against type 1 or 2) experiences a first episode with the opposite HSV type.

Recurrent infection occurs in a person with preexisting antibodies against the same HSV type [1]. Infections during pregnancy may be transmitted to newborns: HSV-1 and
HSV-2 may cause eye or skin lesions, meningoencephalitis, disseminated infections, or foetal malformations.

\section{Epidemiology}

In recent years, genital herpes has become an increasing common sexually transmitted infection. From the late 1970s, HSV-2 seroprevalence has increased by $30 \%$, resulting that one out of five adults is infected $[4,5]$.

HSV seroprevalence in patients with STD varies from $17 \%$ to $40 \%(6 \%$ in the general population and $14 \%$ in pregnant women) $[6,7]$.

Age and sex are important risk factors associated with the acquisition of genital HSV-2 infection. In fact, the prevalence of HSV infection rises with age, reaching the maximum around 40 years [4]. This infection appears related to the number of sexual partners, and regarding sex it is more frequent in women than in men $[8,9]$.

In addition, ethnicity, poverty, cocaine abuse, earlier onset of sexual activity, sexual behavior, and bacterial vaginosis can facilitate a woman's risk of infection before pregnancy $[10,11]$. 
Regarding pregnant population, there is a high prevalence of genital herpes. Among Italian pregnant women, the seroprevalence varies from $7.6 \%$ to $8.4 \%$ seroprevalence [9]. Nevertheless it is lower than that reported among pregnant women in other countries. For example, in US, approximately $22 \%$ of pregnant women are infected with HSV-2, and $2 \%$ of women acquire genital herpes during pregnancy, placing their newborn at risk for herpes infection. In Italy, the number of women who acquire HSV infection during pregnancy is about 3\%. The acquisition of genital herpes during pregnancy has been associated with spontaneous abortion, intrauterine growth retardation, preterm labour, and congenital and neonatal herpes infections [12-14].

The risk of neonatal infection varies from 30\% to $50 \%$ for HSV infections that onset in late pregnancy (last trimester), whereas early pregnancy infection carries a risk of about $1 \%$. When primary HSV infection occurs during late pregnancy, there is not adequate time to develop antibodies needed to suppress viral replication before labour. About $85 \%$ of perinatal transmission occurs during the intrapartum period while transmission of HSV from mother to foetus during pregnancy is less common. Moreover, studies in HIVinfected pregnant women show that coinfection with HSV increases significantly the risk of perinatal HIV transmission above all in women who had a clinical diagnosis of genital herpes during pregnancy [15-17].

The newborn could be also infected by HSV-1, that may represent almost one-third of all new genital HSV diagnoses.

\section{Diagnosis}

Primary symptomatic genital herpes, that occurs after an incubation of a period of $2-20$ days, lasts up to 21 days $[4,18]$. Within women it causes blistering and ulceration of the external genitalia and cervix leading to vulval pain, dysuria, vaginal discharge, and local lymphadenopathy [18]. Vesicular and ulcerative lesions of the internal thigh, buttocks, perineum or in perianal skin are also observed. Both in man and in woman primary infection may be complicated by systemic symptoms such as fever, headache, myalgia (38\% in men, $68 \%$ in women), and occasional meningitis and by autonomic neuropathy resulting in urinary retention, mainly in women $[9,11]$.

All suspected herpes virus infections should be confirmed through viral or serological testing. A diagnosis of genital herpes based on the clinical presentation alone has a sensitivity of $40 \%$ and specificity of $99 \%$ and a false-positive rate of $20 \%$ [19].

The tests used to confirm the presence of HSV infection can be divided into two basic groups: (1) viral detection techniques and (2) antibody detection techniques. Primary viral DNA testing techniques are viral culture and HSV antigen detection by polymerase chain reaction (PCR). The antibody detection techniques include the use of both laboratorybased and point-of-care serologic tests to detect the presence of antibodies to either HSV-1 or HSV-2. With viral detection techniques, negative results do not rule out the presence of infection [20]. The diagnosis of HSV should be confirmed either serologically or with viral culture. Isolation of HSV in cell culture is the preferred virologic test for patients who seek medical treatment for genital ulcers or other mucocutaneous lesions and allows differentiation of the type of virus (HSV-1 versus HSV-2) [21]. The sensitivity of this test is limited because of several issues related to sampling and transportation of the specimen. Additionally, as the lesions heal, they are less likely to be culture positive [21]. Thus, a positive genital culture provides conclusive evidence of genital HSV infection; however, a negative result does not exclude the presence of infection. Polymerase chain reaction techniques involve the amplification of particular sequences of DNA or RNA before detection and can thus detect evidence of viral DNA at low concentrations. In one very large study, PCR results were three to five times more likely to be positive than were cultures. Cultures were more likely to be positive at increasing concentrations of virus. Polymerase chain reaction techniques are commercially available and can differentiate between HSV-1 and HSV-2. Polymerase chain reaction provides increased sensitivity over culture and may ultimately replace culture as the standard of care for diagnosis [22].

At the first prenatal visit also the partner history should be investigated. In case of positive history in the male partner, he should be strongly advised to have no oral and sexual intercourse at the time of recurrence in order to avoid infection (in particular during the third trimester of gestation). Moreover, use of condoms throughout pregnancy should be recommended to minimize the risk of viral acquisition, although the male partner has no active lesions [23].

\section{Congenital and Neonatal Infection}

Itis necessary to distinguish between congenital infection and neonatal infection with HSV. In fact, HSV infection of the newborn can be acquired during pregnancy, intrapartum and postnatally. The mother is the most common source of infection for the first two routes of viral transmission. Congenital infection is very rare due to the acquisition of the virus in utero; it comes to the neonatal HSV infection when the appearances of the lesions are more than 48 hours after birth $[24,25]$.

Intrauterine HSV infection accounts for $5 \%$ of HSV infections in neonates. The highest risk of intrauterine infection has been observed in pregnant (about 50\%) who develop disseminated HSV infections and $90 \%$ of those are related to HSV-2. Both primary and recurrent maternal infection can result in congenital disease, even if the risk after recurrent infection is small.

Intrauterine viral transmission is highest during the first 20 weeks of gestation leading to abortion, stillbirth, and congenital anomalies. The perinatal mortality is 50\% [24].

In $85-90 \%$ of neonatal HSV infections, HSV is acquired at the time of delivery and $5-10 \%$ are caused by early postnatal viral acquisition. A percentage of $70-85 \%$ of neonatal HSV infections are caused by HSV-2, whereas the remaining cases are due to HSV-1. The HSV-2 infection carries a graver prognosis than that caused by HSV-1 [26]. 
The disease transmission to the newborn is dependent on the type of maternal genital infection at the time of delivery.

In fact, neonatal herpes is much more frequent $(50 \%)$ in babies from mothers with a primary HSV infection with respect to babies from mothers with recurrent HSV infection $(<3 \%)$. However, most neonatal HSV infections (about 70\%) result from exposure to asymptomatic genital HSV infection in the mother near delivery [27].

The prolonged rupture of membranes is a risk factor for acquisition of neonatal infection [28]. Congenital intrauterine infection is characterized by skin vesicles or scarring, eye lesions (chorioretinitis, microphthalmia, and cataract), neurologic damage (intracranial calcifications, microcephaly, seizures, and encephalomalacia), growth retardation, and psychomotor development. Infants infected intrapartum or postnatally by HSV can be divided into three major categories:

(1) HSV disease localized to the skin, eye, and/or mouth (SEM); this syndrome is associated with a low mortality but it has a significant morbidity, and it may progress to encephalitis or disseminated disease if left untreated;

(2) HSV encephalitis with or without skin, eye, and/or mouth involvement which causes neurologic morbidity among the majority of survivors;

(3) disseminated HSV which manifests as severe multiorgan dysfunction (including central nervous system, liver, lung, brain, adrenals, skin, eye, and/or mouth) and has a mortality risk that exceeds $80 \%$ in absence of therapy $[27,28]$.

At diagnosis, symptoms are found with the following frequency: skin vesicles $68 \%$, fever $39 \%$, lethargy $38 \%$, seizures $27 \%$, conjunctivitis $19 \%$, pneumonia $13 \%$, and disseminated intravascular coagulation $11 \%$. Symptoms may occasionally be present at birth, but occur in $60 \%$ later than 5 days after birth and sometimes are present after 4-6 weeks of life [21].

Localized infections have been found in 50\% of the affected neonates, involvement of the central nervous system (CNS) in $33 \%$, and disseminated infections in $17 \%$ of the cases $[19,23]$. Several studies have demonstrated that disseminated HSV infections are characterized mainly by liver and adrenals failure associated with shock symptoms and disseminated intravascular coagulopathy [29-31]. Other symptoms of HSV disseminated infection include irritability, seizures, respiratory distress, jaundice, and frequently the characteristic vesicular exanthem that is often considered pathognomonic for infection. However, over $20 \%$ of infants with disseminated infection do not develop skin vesicles during the course of their illness. Encephalitis appears to be a common component of this infection form, occurring in about $60-75 \%$ of infants with disseminated HSV infection.

Mortality in the absence of therapy exceeds $80 \%$ [29]. The prognosis of infants with disseminated HSV disease or neurological manifestations is poor. The mortality in cases with neurological involvement by about $5 \%$ with $50 \%$ of children with neurological sequelae, while in cases with multiorgan involvement mortality, is $30 \%$ and the percentage of sequelae of $20 \%$ [28, 32].

\section{Management of First Infection with HSV in Pregnancy}

In 2008, the Society of Obstetricians and Gynaecologists of Canada published guidelines on the management of HSV in pregnancy [33].

The risk of infection to the infant appears to be higher when the first infection occurs during the third trimester of pregnancy. In this case there may not be sufficient time for the development of maternal IgG and their passage to the fetus, and the risk of neonatal infection is 30 to $50 \%$ [34].

If infection occurs in the first trimester of pregnancy, this seems to be linked to an increase in spontaneous abortions and cases of intrauterine fetal growth restriction. Only in rare cases there is the transmission of the virus transplacentally, resulting in a very severe congenital infection that can occur with microcephaly, hepatosplenomegaly, intrauterine fetal death, and IUGR. The use of antivirals is also permitted in the first trimester of pregnancy if the mother's injuries are particularly serious. At the moment there are enough data to define dell'acyclovir safe to use during pregnancy [35].

When primary infection is acquired during the first two trimesters of pregnancy, it is advisable to carry out sequential viral cultures on genital secretions from 32th week of gestation [36]. Both viral culture that the nucleic acid amplification tests (NAATs) are considered as a test of choice for symptomatic patients. As in Western Europe and the United States, there are no comprehensively validated and approved commercial NAATs available for detection of HSV in many eastern European countries. However, some NAATs for HSV detection have been developed and are available in Eastern Europe, but have not been validated against their internationally acknowledged analogues.

However, if two consecutive cultures result negative and there are no active herpetic genital lesions at the time of delivery, it is possible to perform a vaginal delivery. If seroconversion is completed at the time of delivery, caesarean section is not required since the risk of HSV transmission to the foetus is low, and the neonate should be protected by maternal antibodies.

If primary genital infection is acquired during the third trimester of pregnancy, the optimal way of proceeding is not well defined. Most guidelines propose caesarean section for women developing a primary clinical infection within the last 4-6 weeks of gestation, because they cannot complete their seroconversion prior to the time of delivery, and therefore they could infect the neonates. When vaginal delivery is irreversible, since the risk of vertical transmission is high $(41 \%)$, a maternal and neonatal intravenous acyclovir therapy is recommended [37-39].

\section{Management of Infection Recurrent HSV in Pregnancy.}

A pregnant woman with HSV lesion that has already presented a first infection in the past has circulating $\operatorname{IgG}$, 
TABLE 1: Recommended doses of antiviral medications for herpes in pregnancy [20].

\begin{tabular}{|c|c|c|c|c|c|c|}
\hline \multirow[b]{2}{*}{ Pregnancy } & \multicolumn{3}{|c|}{ First episode } & \multicolumn{3}{|c|}{ Recurrent episodes } \\
\hline & Antiviral drug & $\begin{array}{c}\text { Recommended daily } \\
\text { dosage }\end{array}$ & $\begin{array}{l}\text { Length of } \\
\text { therapy }\end{array}$ & Antiviral drug & $\begin{array}{l}\text { Recommended daily } \\
\text { dosage }\end{array}$ & $\begin{array}{l}\text { Length of } \\
\text { therapy }\end{array}$ \\
\hline \multirow{2}{*}{$\begin{array}{l}\text { Episodic } \\
\text { treatment }\end{array}$} & Acyclovir & Orally: $5 \times 200 \mathrm{mg}$ & 10 days & Acyclovir & Orally: $5 \times 200 \mathrm{mg}$ & 5 days \\
\hline & Valacyclovir & Orally: $2 \times 500 \mathrm{mg}$ & 10 days & Valacyclovir & Orally: $2 \times 500 \mathrm{mg}$ & 5 days \\
\hline \multirow{2}{*}{$\begin{array}{l}\text { Suppressive } \\
\text { treatment }\end{array}$} & Acyclovir & Orally: $3 \times 400 \mathrm{mg}$ & & Acyclovir & Orally: $3 \times 400 \mathrm{mg}$ & \\
\hline & Valacyclovir & Orally: $2 \times 250 \mathrm{mg}$ & $\begin{array}{c}\text { From week } 36 \\
\text { until delivery }\end{array}$ & Valacyclovir & Orally: $2 \times 250 \mathrm{mg}$ & $\begin{array}{c}\text { From week } 36 \\
\text { until delivery }\end{array}$ \\
\hline
\end{tabular}

which are then able to pass the placenta and reach the fetus. It is so unusual that the fetus develops the infection with HSV. If the lesion is present in genital skin during delivery, the risk of infection for the baby will be 2-5\% [28].

Instead, a woman with periodic reactivations of the virus and asymptomatic at birth has a low risk (1\%) to eliminate the virus with vaginal secretions, so the risk of fetal infection is even lower (0.02-0.05\%) [28].

Randomized trials showed that the use of antiviral drugs from the 36th week of pregnancy reduces the risk of spreading of the virus in the absence of clinically visible lesions and the risk of viral reactivation with decreased percentage of caesarean sections [21].

The use of antiviral drugs is allowed before the 36th week in case of very serious events in the mother, or if there is an increased risk of preterm delivery.

The therapy includes the administration of acyclovir $400 \mathrm{mg}$ tablets 3 times daily or acyclovir $200 \mathrm{mg}$ tablets 4 times a day from week 36 until delivery, and viral cultures on cervical-vaginal secretions from 36 th week of gestation are required. Recent studies also suggest the use of valacyclovir at a dose of $200 \mathrm{mg} 2$ times a day.

In absence of clinical herpes lesions but with positive viral cultures at delivery, caesarean section is recommended. On the contrary, if all viral cultures are negative, in the absence of clinical lesions, a spontaneous delivery is indicated.

Finally, in presence of clinical genital HSV lesions at the onset of delivery, if it may be assumed that the foetal lungs are mature, a caesarean section should be performed as quickly as possible within 4-6 hours after membranes rupture [20, $21,34]$.

\section{Therapy}

Pregnant women with a first clinical episode or a recurrence may be treated with acyclovir or valacyclovir at the recommended dosages (Table 1). Since acyclovir and valacyclovir are not officially approved for treatment of pregnant women, patients should be informed to give consent before the administration [20]. However, no increase of foetal abnormalities was ascribed to these treatments, although longterm outcomes were not evaluated [20].

Treatment with acyclovir and valacyclovir by 36 weeks of pregnancy to term reduces the frequency of clinical manifestations, vertical transmission, elimination of the virus during birth by reducing the percentage of caesarean (Table 1) [28].

\section{Conclusions}

Genital herpes is a preventable chronic disease. Although most HSV infections are subclinical, clinical disease can be associated with substantial physical and psychosocial morbidity. The clinical manifestations are diverse; hence a suspected diagnosis of HSV should be confirmed by laboratory tests. The management of genital herpes should be tailored to the individual and should include counselling about the variable natural history appearance of lesions, education about prevention of transmission, the link between HSV and HIV, and discussion to assess the psychosexual effects of the disease. Antiviral therapy is safe and effective, both for episodic treatment and chronic suppression of HSV.

A large amount of information on the transmission of herpes from male to pregnant partner, on the mode of transmission from mother to newborn, mainly by maternal firsttime infection in the third trimester of pregnancy, has been published in literature.

Since the increasing prevalence of genital HSV infection and apparent increase in the incidence of neonatal herpes, we have focused our attention on prevention of maternal foetal transmission as well as on the management of infected pregnant women and neonate. Further studies are needed to monitor the changing HSV-1 and HSV-2 trends and to develop effective strategies to prevent HSV infection. Finally, the major vaccine strategies under development should take in to account the three important features of herpesviruses: the viral latency, the herpes immune escape, and the high seroprevalence.

\section{References}

[1] R. Gupta, T. Warren, and A. Wald, "Genital herpes," The Lancet, vol. 370, no. 9605, pp. 2127-2137, 2007.

[2] G. Paz-Bailey, M. Ramaswamy, S. J. Hawkes, and A. M. Geretti, "Herpes simplex virus type 2: epidemiology and management options in developing countries," Sexually Transmitted Infections, vol. 83, no. 1, pp. 16-22, 2007.

[3] C. M. Roberts, J. R. Pfister, and S. J. Spear, "Increasing proportion of herpes simplex virus type 1 as a cause of genital herpes infection in college students," Sexually Transmitted Diseases, vol. 30, no. 10, pp. 797-800, 2003.

[4] M. Cusini and M. Ghislanzoni, "The importance of diagnosing genital herpes," Journal of Antimicrobial Chemotherapy, vol. 47, no. 1, pp. 9-16, 2001. 
[5] H. Weiss, "Epidemiology of herpes simplex virus Type 2 infection in the developing world," Herpes, vol. 11, supplement 1, pp. 24A-35A, 2004.

[6] M. Cusini, M. Cusan, C. Parolin et al., "Seroprevalence of herpes simplex virus type 2 infection among attendees of a sexually transmitted disease clinic in Italy," Sexually Transmitted Diseases, vol. 27, no. 5, pp. 292-295, 2000.

[7] A. L. Cunningham, F. K. Lee, D. W. Ho et al., "Herpes simplex virus type 2 antibody in patients attending antenatal or STD clinics," Medical Journal of Australia, vol. 158, no. 8, pp. 525528, 1993.

[8] J. S. Smith and N. J. Robinson, "Age-specific prevalence of infection with herpes simplex virus types 2 and 1: a global review," Journal of Infectious Diseases, vol. 186, supplement 1 , pp. S3-S28, 2002.

[9] B. Suligoi, M. Cusan, P. Santopadre et al., "HSV-2 specific seroprevalence among various populations in Rome, Italy. The Italian herpes management forum," Sexually Transmitted Infections, vol. 76, no. 3, pp. 213-214, 2000.

[10] T. L. Cherpes, L. A. Meyn, M. A. Krohn, J. G. Lurie, and S. L. Hillier, "Association between acquisition of herpes simplex virus type 2 in women and bacterial vaginosis," Clinical Infectious Diseases, vol. 37, no. 3, pp. 319-325, 2003.

[11] S. L. Gottlieb, J. M. Douglas Jr., D. S. Schmid et al., "Seroprevalence and correlates of herpes simplex virus type 2 infection in five sexually transmitted-disease clinics," Journal of Infectious Diseases, vol. 186, no. 10, pp. 1381-1389, 2002.

[12] M. Arvaja, M. Lehtinen, P. Koskela, M. Lappalainen, J. Paavonen, and T. Vesikari, "Serological evaluation of herpes simplex virus type 1 and type 2 infections in pregnancy," Sexually Transmitted Infections, vol. 75, no. 3, pp. 168-171, 1999.

[13] A. Ciavattini, M. Vichi, A. Rinci, and D. Tsiroglou, "Infezioni virali in gravidanza: gestione e raccomandazioni," La Colposcopia in Italia, vol. 2, pp. 11-16, 2007.

[14] Z. A. Brown, S. Selke, J. Zeh et al., "The acquisition of herpes simplex virus during pregnancy," The New England Journal of Medicine, vol. 337, no. 8, pp. 509-515, 1997.

[15] Centers for Disease Control and Prevention Website, Sexually transmitted disease guidelines, http://www.cdc.gov/std/treatment/2006/rr5511.pdf.

[16] A. M. Enright and C. G. Prober, "Neonatal herpes infection: diagnosis, treatment and prevention," Seminars in Neonatology, vol. 7, no. 4, pp. 283-291, 2002.

[17] K. T. Chen, M. Segú, L. H. Lumey et al., "Genital herpes simplex virus infection and perinatal transmission of human immunodeficiency virus," Obstetrics and Gynecology, vol. 106, no. 6, pp. 1341-1348, 2005.

[18] U. Desselberger, "Herpes simplex virus infection in pregnancy: diagnosis and significance," Intervirology, vol. 41, no. 4-5, pp. 185-190, 1998.

[19] A. Sauerbrei and P. Wutzler, "Herpes simplex and varicellazoster virus infections during pregnancy: current concepts of prevention, diagnosis and therapy. Part 1: herpes simplex virus infections," Medical Microbiology and Immunology, vol. 196, no. 2, pp. 89-94, 2007.

[20] Centers for Disease Control and Prevention, "Sexually transmitted diseases treatment guidelines," Morbidity and Mortality Weekly Report, vol. 55, no. RR-11, pp. 1-94, 2006, Published erratum appears in Morbidity and Mortality Weekly Report, vol. 55, pp. 997, 2006.

[21] A. Berardi, L. Lugli, C. Rossi et al., "Neonatal herpes simplex virus," Journal of Maternal-Fetal and Neonatal Medicine, vol. 24, supplement 1, pp. 88-90, 2011.
[22] M. Domeika, M. Bashmakova, A. Savicheva et al., "Guidelines for the laboratory diagnosis of genital herpes in easternEuropean countries," Eurosurveillance, vol. 15, no. 44, Article ID 19703, 2010.

[23] S. Büchner, P. Erni, J. Garweg et al., "Swiss recommendations for the management of genital herpes and herpes simplex virus infection of the neonate," Swiss Medical Weekly, vol. 134, no. 15-16, pp. 205-214, 2004.

[24] D. Money and M. Steben, "Guidelines for the management ofherpes simplex virus in pregnancy," International Journal of Gynecology \& Obstetrics, vol. 104, no. 2, pp. 167-171, 2009.

[25] R. J. Whitley and J. W. Gnann Jr., "Herpes simplex virus," in Mucocutaneous Manifestations of Viral Diseases, S. K. Tyring and A. Yen-Moore, Eds., pp. 69-117, Informa Health Care, New York, NY, USA, 2002.

[26] M. Avgil and A. Ornoy, "Herpes simplex virus and EpsteinBarr virus infections in pregnancy: consequences of neonatal or intrauterine infection," Reproductive Toxicology, vol. 21, no. 4, pp. 436-445, 2006.

[27] ACOG Practice Bulletin, "Clinical management guidelines for obstetrician-gynecologists. No. 82 June 2007. Management of herpes in pregnancy," Obstetrics and Gynecology, vol. 109, no. 6, pp. 1489-1498, 2007.

[28] E. Anzivino, D. Fioriti, M. Mischitelli et al., "Herpes simplex virus infection in pregnancy and in neonate: status of art of epidemiology, diagnosis, therapy and prevention," Virology Journal, vol. 6, no. 6, article 40, 2009.

[29] R. J. Whitley and J. W. Gnann Jr., "Herpes simplex virus," in Mucocutaneous Manifestations of Viral Diseases, S. K. Tyring and A. Yen-Moore, Eds., pp. 69-117, Informa Health Care, New York, NY, USA, 2002.

[30] A. Meerbach, A. Sauerbrei, W. Meerbach, H. J. Bittrich, and P. Wutzler, "Fatal outcome of herpes simplex virus type 1induced necrotic hepatitis in a neonate," Medical Microbiology and Immunology, vol. 195, no. 2, pp. 101-105, 2006.

[31] D. S. Greenes, D. Rowitch, G. M. Thorne, A. Perez-Atayde, F. S. Lee, and D. Goldmann, "Neonatal herpes simplex virus infection presenting as fulminant liver failure," Pediatric Infectious Disease Journal, vol. 14, no. 3, pp. 242-244, 1995.

[32] R. Whitley, "Neonatal herpes simplex virus infection," Current Opinion in Infectious Diseases, vol. 17, no. 3, pp. 243-246, 2004.

[33] D. Money and M. Steben, "Guidelines for the management of herpes simplex virus in pregnancy," Obstetrics \& Gynecology Journal, vol. 30, no. 6, pp. 514-519, 2008.

[34] C. Gardella and Z. Brown, "Prevention of neonatal herpes," Journal of Obstetrics and Gynaecology, vol. 118, no. 2, pp. 187192, 2011.

[35] L. Corey and A. Wald, "Maternal and neonatal herpes simplex virus infections," The New England Journal of Medicine, vol. 361, no. 14, pp. 1328-1385, 2009.

[36] A. Ciavattini, M. Vichi, A. Rinci, and D. Tsiroglou, "Infezioni virali in gravidanza: gestione e raccomandazioni," La Colposcopia in Italia, vol. 2, pp. 11-16, 2007.

[37] C. M. Rudnick and G. S. Hoekzema, "Neonatal herpes simplex virus infections," American Family Physician, vol. 65, no. 6, pp. 1138-1142, 2002.

[38] J. M. Kriebs, "Understanding herpes simplex virus: transmission, diagnosis, and considerations in pregnancy management," Journal of Midwifery and Women's Health, vol. 53, no. 3, pp. 202-208, 2008. 
[39] A. Meerbach, A. Sauerbrei, W. Meerbach, H. J. Bittrich, and P. Wutzler, "Fatal outcome of herpes simplex virus type 1induced necrotic hepatitis in a neonate," Medical Microbiology and Immunology, vol. 195, no. 2, pp. 101-105, 2006. 


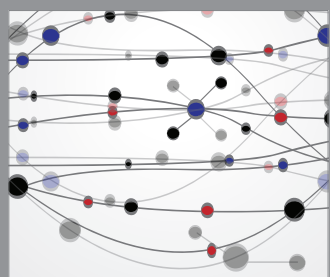

The Scientific World Journal
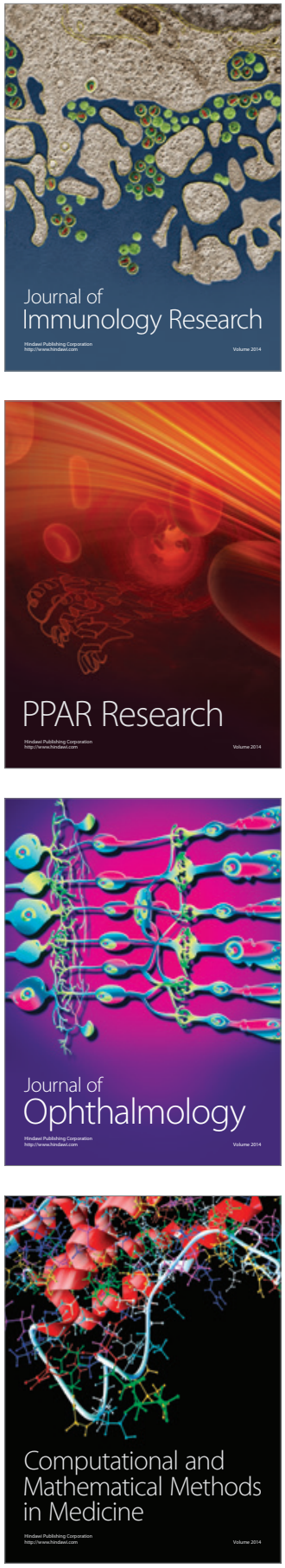

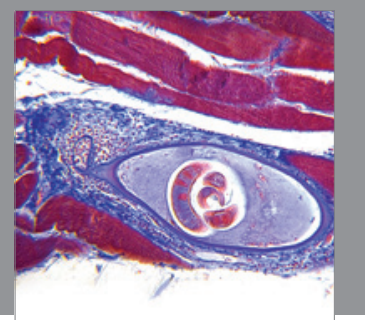

Gastroenterology

Research and Practice
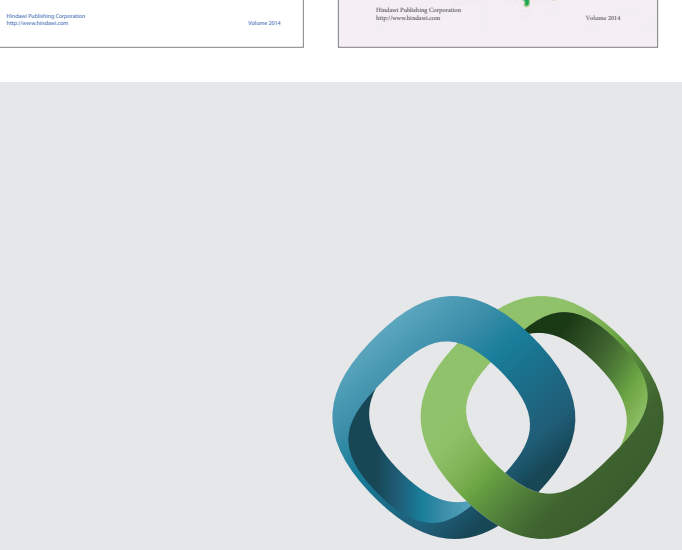

\section{Hindawi}

Submit your manuscripts at

http://www.hindawi.com
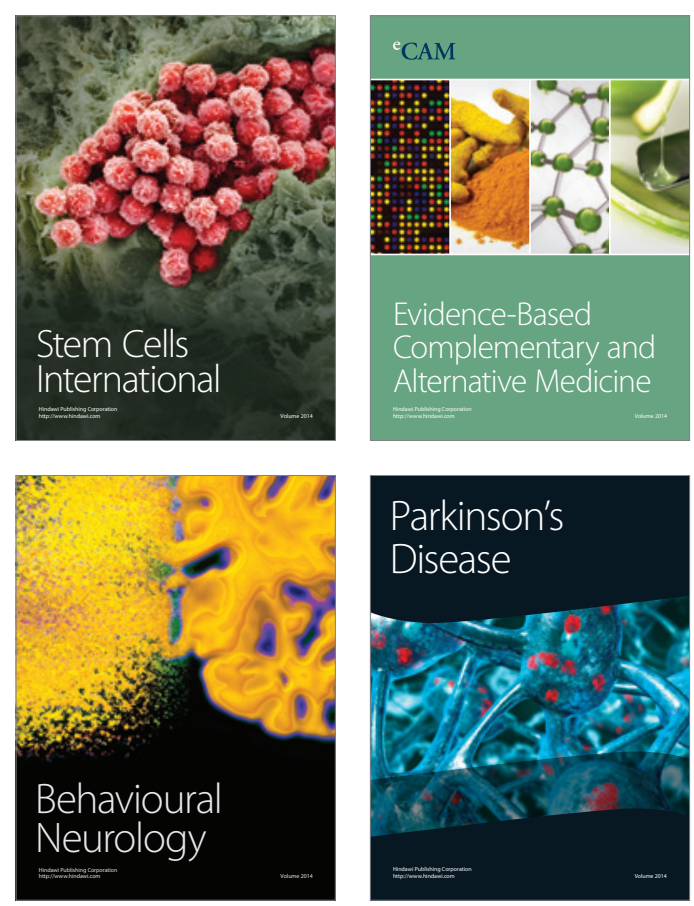

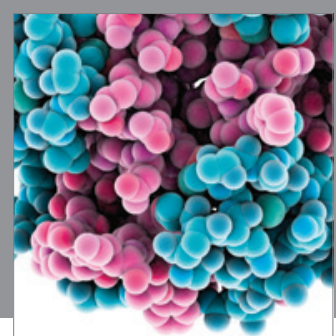

Journal of
Diabetes Research

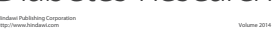

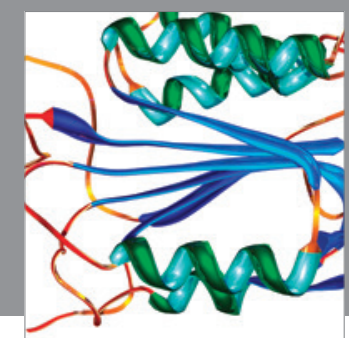

Disease Markers
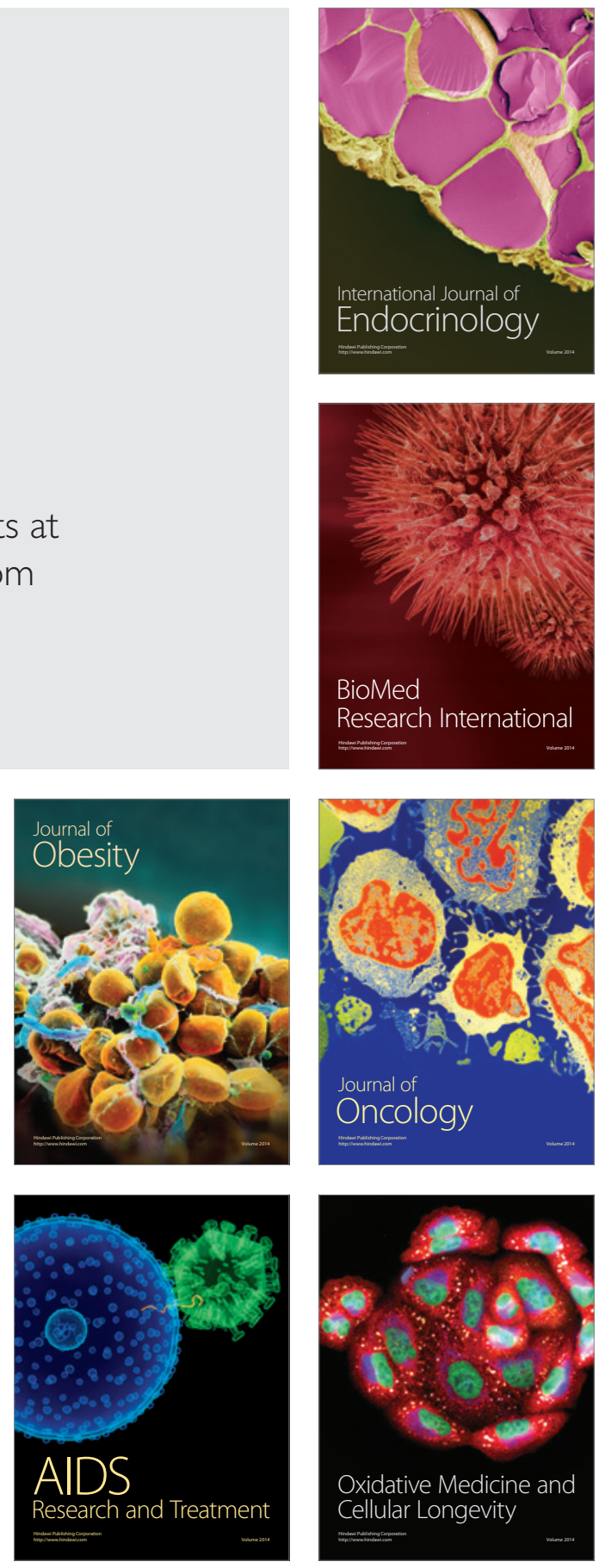